RADMILA BURKOVIČOVÁ

University of Ostrava

\title{
CHANGES IN THE EDUCATIONAL PRACTICE IN KINDERGARTENS IN THE CZECH REPUBLIC
}

\begin{abstract}
Burkovičová Radmila, Changes in the Educational Practice in Kindergartens in the Czech Republic [Zmiany w praktyce w przedszkolach w Republice Czeskiej]. Studia Edukacyjne nr 42, 2016, Poznań 2016, pp. 471-485. Adam Mickiewicz University Press. ISSN 1233-6688. DOI: 10.14746/ se.2016.42.27

Relatively extensive changes are currently taking place in the system of preschool education in the Czech Republic, which will mainly affect the educational landscape of kindergartens. A personalityoriented model of preschool education requires a considerate, understanding and helping approach to each child. The joint education of all children, where inclusion occurs for certain children who were excluded from children's communities in the past, is happening within the context of Czech and international legislation. Supporting measures are provided to children where required. However, such measures may ultimately also benefit the teacher.
\end{abstract}

Key words: change, kindergarten, inclusive education, awareness raising, child, respondent

\section{Introduction}

For various reasons, at regular intervals, education in the Czech Republic gets into the centre of attention of both experts and the lay public. The factors in this process vary. The current actor drawing the public's attention to the educational system is the Ministry of Education, Youth and Sport. One of the priorities highlighted by the Ministry is joint education of children, pupils and students within the main educational stream. Joint education denotes bringing all children with varying educational needs together within common classes. There will probably always be a certain proportion of children, with regard to whom the parents, teachers, physicians and psychologists will agree they will flourish in a special school setting. In Europe, how- 
ever, the Czech Republic has the third highest proportion of children excluded from the main educational stream. Children with physical handicaps and sensory impairments, who may not be expected to meet the cognitive requirements of tuition, are not included in classes at regular primary schools. Until now, they have been placed in special schools. The education of Roma children is a separate issue. The long-term aim is for common schools offering high-quality tuition to become a first choice ${ }^{1}$ for all children, except for when medically justified otherwise. The special schools are retained within the education system.

The frequency of discussions on joint education in the Czech society has markedly grown during the last two years. Representatives of the academia; the Czech Professional Society for Inclusive Education; representatives of schools, parents and young people with special educational needs (hereinafter also referred to as SENs) believe that inclusive education is a way of achieving higher quality and fairness in education. The aim of joint education is to maximise the educational potential of each child - if possible among their natural peers. Considering the segregationist nature of the entire Czech educational system, manifesting itself through the existence of extended grammar schools and specialised schools for the gifted, and taking into account the right of the parent to choose their child's school, the society views the Ministry's activity as an effort at a systemic change.

Change is a generic name for an observable and identifiable transition from a certain quality, state or characteristic of an object to another quality, state or characteristic. It tends to be viewed as an expressionof advancement or progress, but it may also be a sign of regression. It happens over time, has a direction and takes place in steps, which may have various intensities. If a change is quantifiable, it is either an increment, or a reduction. ${ }^{2}$ As individualities, the people concerned tend to view the change in different ways. The evaluation of a change, which should be undertaken on the basis of the information available, tends to be highly subjective and often ambiguous, and individuals may use it to express their attitude to the change. As a rule, they then act in keeping with their expressed attitudes, also considering the effects of their action. Based on new information obtained, for which source credibility, content of the message and also other factors play a major role,

1 Open Society Fund Praha. Do all children have equal educational opportunities? http://osf.cz/cs/co-delame/vzdelavani-deti-a-mladych-

lidi/?utm_source $=$ adwords\&utm_medium $=p p c \& u t m \_c o n t e n t=$ otevrenaskola\&utm_campaign =S_Podporte\&gclid=CjwKEAiA7ejCBRDlp8uF6ezPnjoSJAAPED7MD-57vm56wy8v4W1Y

AL8zTSo0AbC-WrprylpFvmCo8BoCSq_w_wcB). [available: 18 January 2017].

2 W. Brugger, Filosofický slowník, Naše vojsko, Praha 1994. 
the individual may change their attitude. A change of attitude will manifest itself as a change of behaviour. ${ }^{3}$ In the context of education, the change currently taking place is viewed as a new or a changed attitude of individuals to education of handicapped children, pupils and students, expressed by the acceptance of the concept of inclusive education for all within the main educational stream in common classrooms facilitated through the adoption of so-called supporting measures.

\section{Legislative backing of changes in children's education}

Joint education is supported by both national regulations, especially (a) the Education Act, as amended, ${ }^{4}$ the Decree (b) concerning the education of pupils with special educational needs and gifted pupils and the Decree c) on the provision of counselling services at schools and school counselling establishments. When implementing the changes, Czech legislation is mainly based on the following international documents: The Universal Declaration of Human Rights adopted by the UN in 1948, the UN Convention on the Rights of the Child of 1989, the UNESCO Salamanca Statement of 1994, the World Declaration on Education for All, or the so-called Jomtien Declaration of 1990 andthe UN Convention on the Rights of People with Disabilities of 2006.

The Decree referred to under b) establishes one of the main underlying concepts of joint education, namely that all children are educated in a "common classroom setting". At the same time, however, it formulates an idea that the common classroom setting must not limit a handicapped child in any way. The setting will be recommended by a school counselling establishment. Therefore, if a child with a handicap does not feel comfortable in the common classroom setting, and the latter cannot be modified for any reason, the child must be placed at a school, the setting of which reflects the child's specific handicap. The condition is that the child's legal guardian applies for their child to be educated in the given class and attaches a recommendation of the relevant school counselling establishment to their application. However, children without a mental handicap are not placed in classrooms for children with mental handicaps.

3 J. Průcha, E. Walterová, J. Mareš, Pedagogický slovník, Portál, Praha 2008, p. 171.

${ }^{4}$ Ministry of Education, Youth and Sport. Act No. 561/2004 Coll. on preschool, primary, secondary, higher vocational and other education (Education Act), http://www.msmt.cz/dokumenty3/skolsky-zakon-ve-zneni-ucinnem-od-1-1-2017-do-31-8-2017, [available: 18 January 2017]. 
Preschool education supports development of perception, thinking, attention, motor skills and helps stipulate development. The current education model for preschool children is personality-oriented at Czech kindergartens, which calls for a considerate, understanding and helping approach to all children. The aim of all changes related to the concept of joint education is to create such educational conditions for kindergarten children that reflect their capacities, their needs in relation to their age, which respect the depth of their talent and the impacts of their health state in the process of their preparation for school. The changes include interventions to support the impaired skills of the children by including practical activities in the curriculum.

\section{Supporting Measures}

With effect as of 1 September 2016, the Amendment to the Education Act guarantees the right of children to so-called supporting measures, the purpose of which it is to overcome the children's handicaps. The first level of support mainly consists in developing an educational support plan (hereinafter also referred to as PPP) for the child, which involves making methodological adjustments to the educational process and its application; regular mutual consultations of the educational staff with evaluation of the methods employed and material support depending on the structural nature of the school. 5 The second level of support includes educational and other recommendations and the appointment of a specific staff member of a school counselling establishment responsible for communication with the school, and individuals providing counselling services to the school as part of their expertise, for the purposes of educating gifted children; where necessary, a child may be assigned to a special educational or educational intervention care programme depending on the composition of the child's difficulties.

The third level of support is applied on recommendation of a school counselling establishment. Depending on the composition of the child's special educational needs and on the capacities of the kindergarten concerned, the child may be assigned to a special educational or educational intervention care programme. In their work, the teacher is supported by a teacher assistant, a school psychologist, or a special education teacher for up to 4 children per class, it being understood that the special educational

${ }^{5}$ Ministry of Education, Youth and Sport. Decree No. 27/2016 Coll., on the education of pupils with special educational needs and gifted pupils, http:/ / www.msmt.cz/dokumenty-3/vyhlaska-c27-2016-sb-o-vzdelavani-zaku-se-specialnimi, [available: 18 January 2017]. 
needs of the children, for whom the teacher's support by a teacher assistant is sought, do not necessarily have to be of the same kind. If there are more then 4 children with special educational needs in a class, or if the teacher's support by an assistant teacher is no long sufficient, another teacher may be introduced in the educational process.

Unlike for the levels of support referred to above, at the fourth level, the school counselling establishment becomes the coordinator of the care. In addition to teacher assistants, it is possible to use an interpreter into the Czech sign language, a special education teacher, a school psychologist or other educational workers. Special education centre's services concerning the child's spatial orientation are available and methodological support is provided to the kindergarten's educational workers. Educational or school services at this level are only provided in premises that have been structurally or technically adapted.

Fifth-level support measures are reserved for children with combined handicaps. These children are not placed in kindergartens for now. ${ }^{6}$

The range of supporting measures selected always respects the children's age and specific features. Naturally, the cooperation of teachers and all professionals with the child's legal guardians is indispensable at all levels of the support provided, both when applying the child's support and when conducting regular efficiency reviews for the supporting measures selected for the child, depending on the character of the child's SEN. If the support provided is terminated, it is the kindergarten's obligation to notify the child's legal guardian thereof.

\section{Methodology}

The survey focused on the level of awareness of the changes in the area of education of children with SENs for two groups of respondents, namely kindergarten teachers, principals and head teachers ${ }^{7}$ enrolled in the combined form of the Kindergarten Teacher Training course at the Pedagogical Faculty of the University of Ostrava, and kindergarten teachers, principals and head teachers who have not yet enrolled in the course.

${ }^{6}$ Ministry of Education, Youth and Sport. Decree No. 72/2005 Coll. concerning the provision of $c$ counselling services at schools and school counselling establishments, https://www.zakony prolidi.cz/cs/2005-72,[available: 18.01.2017].

7 J. Michalík, P. Baslerová, L. Felcmanová, Podpưrná opatření ve vzdělávání, Člověk v tísni, o. p. s., Praha 2015, p. 11. 
It will be mainly kindergarten principals or head teachers who will introduce, or are already introducing, the changes in practice, and the teachers specifically will implement, or are implementing them as part of their direct work with the children. All groups of educational workers are expected to be informed, i.e., professionally and legislatively aware of the changes so that they could apply them in practice. Also, they are expected to be ready, in educational terms, to handle, along with the children, their parents and other stakeholders, the social and educational situations that may occur in connection with the changes in the educational system.

In the Czech Republic, graduates from secondary schools focusing on preschool children's education also become qualified and enter the educational practice. After that, they may enrol in kindergarten teacher training courses at the Baccalaureate level and, subsequently, in preschool age education courses at the Master's level, at pedagogical faculties.

At the Pedagogical Faculty in Ostrava, information on the changes in the educational system are provided under several courses of study, as shown in the respective syllabuses.

Therefore, the principal question was:

Do the educational workers currently enrolled in the combined-form Kindergarten Teacher Training course at the Pedagogical Faculty of the University of Ostrava show better awareness of the changes than the educational workers who have not yet enrolled in the course?

The principle question gave rise to a score of specific questions. For example, what do the educational workers consider to be a change in the preschool children's education system? How and where do they get information on the changes in the educational system? How are the changes in the preschool children's education prepared? What do they know about the educational support plan?

The assumption was that there would be no statistically significant differences between the frequencies of responses between the two groups of respondents and that both groups of respondents will display the same level of awareness. The assumption is based on the fact that both groups of respondents are active in the educational field, sharing the same informational, legislative, educational and social environment.

We will base the analysis on the paradigm of interpretative sociology. There is an interest in establishing how the targeted social reality (awareness of the changes in the system of educating children) is viewed and interpreted by the two groups of educational workers. 


\section{Object of research, research tool, research sample}

A quantified questionnaire survey was undertaken. The first group of respondents were field educational workers (hereinafter referred to as RT respondents teachers). Using a directory of kindergartens available, a hundred schools were addressed via email in October and November 2016. The assumption that one response only would be obtained from each kindergarten proved correct; 98 responses were obtained in total. For information: $17(20.73 \%)$ questionnaires were returned by kindergartens that have more than four classes, $17(20.73 \%)$ from kindergartens with four classes, 25 $(30.48 \%)$ from kindergartens with three classes, and 27 (32.93\%) and 12 $(14.63 \%)$ from kindergartens with two classes and one class, respectively. In 16 out of 98 questionnaires the respondents filled in university education under the item dedicated to the respondent's completed education. Considering the aim of the research, these questionnaires were set aside; as a result, responses from 82 questionnaires were processed.

The other group of respondents (hereinafter referred to as "RS respondents students") was composed of students of the combined-form study programme referred to above, as they registered, on a voluntary basis, for the research from all years of study before the same number of respondents as for the RT group was achieved. They filled in the questionnaire within the same time limit, in a classroom, individually and without being able to cooperate with one another. The electronic, non-standardised questionnaire contained 20 items, a part of them closed - they were dichotomous, polytomic multiple-choice questions, multiple-option questions; a part of them encouraged loose responses. In order to secure the proper formulation of the questions, piloting was used and taken part in by full-time students.

As regards the RT group, the managements of kindergartens chose not to ask teachers-beginners with less than 2 years of experience to answer the questions. Depending on the length of their educational experience, the responses were given by 19 educational workers with 2 to 5 years of experience $(23.17 \%), 14$ educational workers with 6 to 10 years of experience $(17.07 \%), 33$ educational workers with 11 to 15 years of experience $(40.24 \%)$; 31 educational workers with 16 to 20 years of experience $(37.80 \%)$ and only 1 educational worker over 20 years of experience $(1,22 \%)$. It has been shown that based on their length of experience, the kindergarten managements mostly trusted educational workers with medium length of experience to answer the questions. They are experienced, professionally consolidated workers who-considering their professional presence and future - should be interested in the current situation and trends in their field. 
In the RS group, 25 students (30.48\%) had 2 to 5 years of experience, 34 students $(41.46 \%)$ had 6 to 10 years of experience; 16 students $(19.51 \%)$ had 11 to 15 years of experience; 7 students $(8.54 \%)$ had 16 to 20 years of experience and none of the students reported over 20 years of experience.

The relationship between the length of educational experience and awareness will be analysed at the next data processing stage.

\section{Results and analysis of the data obtained}

Some results are given. Based on the frequencies obtained, values were calculated for the relevant data $\chi^{2}$. The values were compared to the critical value for the selected level of importance and a decision to accept or not to accept the hypothesis was made. The data obtained from the loose answers were subjected qualitative classification. In the verbal reports, answers similar in meaning were identified with the same symbol; then they were analysed and the basic analytical units, i.e. concepts and categories, were derived. After that, they were used for a re-analysis. The results were turned into quantitative processing.

The following data were obtained from answers to the question as to what the teachers considered as a change in preschool children's education:

The placement of children with any handicap or disorder among healthy children in regular classrooms was regarded as a change by $57 \mathrm{~T}$ respondents $(69.51 \%)$ and $68 \mathrm{~S}$ respondents S (83.93\%).

Legislative amendments are regarded as a change by $64 \mathrm{RT}$ respondents $(78,05 \%)$ and 74 RS respondents $(90.24 \%)$. This category reported the highest frequency among respondents assigned to both groups.

Involvement of a teacher assistant in the educational process was also regarded as a major change by the respondents. It was labelled as such by 54 RTs $(65.85 \%)$ and 64 RSs (70.05\%). It may be assumed that the respondents thought of the availability of the assistant rather than anything else, since teacher assistants have been available ever since 2004. But it was hardly ever possible to get one, due to financial reasons.

Based on the frequency at which it was indicated by the respondents (48 RTs $(58.54 \%)$ and 51 RSs (\%)), development of educational support plans placed fourth in the ranking.

Increased demands for teachers by parents were regarded as a chance by 39 RTs (47.56\%), but 49 RSs (59.76\%). 
49 RT teacher respondents (59.76\%) and 47 RS students respondents $(57.32 \%)$ considered involvement of school counselling establishments in cooperation with the kindergartens as a novelty.

The same number of RTs, 49 (59.76\%) viewed as a change the requirements for regular mutual consultations of educational workers. In the RS group, 35 respondents (42.68\%) viewed this as a change.

Among other changes identified were the attention the media, parents, and politicians devoted to children with SENs. The frequencies reported greatly differed between the groups though. In the RT group, 54 respondents $(65.85 \%)$ considered this as a change, while in the RS group, only 14 (17.07\%) respondents did.

Material help in the event of the placement of children with SENs was viewed as a change by 16 respondents (19.51\%) in the RT group and 23 respondents $(28.05 \%)$ in the RS group. Some respondents prefixed the expression "material help" by the word "offer" without substantiating the addition. In this way they sounded their concern based on previous experience that this change would not materialise.

The last category established contains changes in the number of children in classes after SEN children are included. This category was mentioned by 17 RTs $(20.73 \%)$ and 23 RSs $(28.05 \%)$.

Based on the calculated value $\chi^{2}$ the two groups were statistically proven to display the same level of awareness in most categories, except for two, namely the attention of the media, parents and politicians and the change in the number of children in the classes after SEN children are included.

The respondents were further required to identify their source of information on the changes, from which they get information on joint education. Regional Educational Centres (hereinafter referred to as KVCs) operate at the regional level, and their mission is to provide updated, professional, high-quality information. Based on the frequency of the responses given by the RT group, however, the KVCs only placed fourth, with 23 picks $(28.05 \%)$. In the RT group, searching at the Internet was picked 78 times (95.12\%), specialised press 48 times (58.54\%), TV and other media 33 times (40.24\%), kindergarten management 11 times $(13.41 \%)$ and colleagues 10 times $(12.20 \%)$.

The RS group's responses were different in terms of percentages, but the resulting ranking was identical. The KVC was picked 5 times (6.1\%); still higher than that, searching at the Internet was picked 81 times $(89.78 \%)$, specialised press 32 times (39.02\%), TV and other media 15 times (18.29\%), kindergarten management 5 times $(6.1 \%)$ and colleagues 4 times (4.88\%). 
The difference in obtaining information from KVC actors; TV and other media; and colleagues is statistically significant. The differences between the groups in reliance upon the other actors are not statistically significant. The preference for the Internet is significant in the RS group. With the frequencies of their responses, both groups communicate that kindergarten principals do not provide their inferiors with sufficient information on changes in the educational system.

Kindergarten teachers have encountered the following special educational needs of children (diagnosed by professionals) in the course of their educational practice after the system changes:

RT group and RS group respondents reported impaired communication skills for 45 and 72 children, respectively; hearing impairments and weakened auditory perception were reported for 9 children by RTs and 2 children by RSs; physical handicaps were reported for 7 children by RTs and 4 children by RSs; RTs and RSs reported 25 and 42 children, respectively, with the autism spectrum disorder; specific behavioural disorder was reported for 12 children by RTs and 11 children by RSs; different living conditions were reported for 27 children by RTs and 4 children by RSs; visual impairment was reported for 6 children by RTs and 17 children by RSs; mental handicap was for 11 children by the RTs and 5 children by RSs. The RT group reported combined handicaps for 1 child, while the RT respondents did to not report meeting any child with this specific disorder.

It should be noted that Czech kindergartens have always been most welcoming to children and their parents. Czech teachers regularly accepted children with SENs even before the onset of this era which specifically concentrates on assigning children with SENs in common classrooms. They have established a practice of including these children among the other children, individually dealing with the children and providing both professional and human assistance to the parents.

In response to a question as to what issues they face when dealing with children with SENs within the educational process, the respondents shared their experience with children with ADHD, who they referred to as being educationally unmanageable - RT 14 (17.07\%), RS 17 (20.73\%), children with behavioural disorders - RT 35 (42.68\%), RS 6 (7.31\%) and children with autistic spectrum disorders - RT 5 (6.10\%), RS 11 (13.41\%). These did not concern current cases, but rather their existing professional experience.

The respondents gave the following specific issues observed when dealing with children with SENs:

High degree of inattention of SEN children during the educational process in general - RT 48 (58.54\%), RS 54 (65.85\%). 
Their own inability to evenly distribute their attention among all children (including those without SENs diagnosed) according to their requirements - RT 75 (91.46\%), RS 62 (75.61\%).

Problems involving cooperation with both the parents of children not diagnosed with SENs and parents of children diagnosed with SENs within classrooms to which SEN children have been assigned - RT 22 (36.83\%), RS $38(46.34 \%)$.

Higher incidence of collisions and conflicts among children, which the teachers must deal with since the children are unable to do so on their own RT 48 (58.54\%), RS 23 (28.05\%).

Missing methodological guidance - RT 78 (95.12\%), RS 54 (65.85\%).

The last three problems identified (problematic cooperation...; higher incidence ...; missing methodology...) are reported as problems by the respondents with varying frequencies and the difference is statistically significant. For the first two problems, the frequency is subject to multiple external factors. The third problem involves a situation inside the educational system. This is a red flag for the governing bodies, including principals and head teachers, but also for all institutions whose mission is to provide further training to educational workers. The high incidence of problems also implies an irregularity in the training system in the kindergarten teacher training study programme. Respondents who are enrolled in a university course report missing methodological guidance. For the other problems reported, the difference in frequencies given by the two groups is not statistically significant, which does not mean that the problems are not significant as such. Globally speaking, each problem identified and each problem selected points to an irregularity which should be addressed.

The other questionnaire items focused on identifying how the respondents prepare for changes in the system of educating preschool children in their own professional practice. Generally, the following information was obtained on the educational support plan (hereinafter referred to as "PPP"):

All 82 RTs (100\%) and 65 RSs (79.27\%) reported to have educational support plans prepared for individual children. In statistical terms, the fact that out of 82 respondents only 65 (RS) reported to have an educational support plan ready is not significant.

78 RTs $(95.12 \%)$ and 79 RSs $(96.34 \%)$ confirmed they were aware of the difficulties and SENs of the children assigned to their classes.

All of them, i.e. 82 RTs and 82 RSs, reported that all kindergarten teachers had been made familiar with the PPP.

48 RT respondents (58.54\%) RT a 51 RS respondents $(62.20 \%)$ agreed that the child's legal guardians were made familiar with the educational support 
plan at their kindergartens. 32 (39.02\%) RTs and 12 RSs (14.63\%) thought that the familiarisation occurred. The rest, i.e. 2 RTs $(2.44 \%)$ and 19 RSs $(23.17 \%)$ did not know whether the child's legal guardians were familiar with the PPP at their kindergartens.

It should be noted that the fact that out of 65 respondents, whose kindergartens have prepared educational support pans, 19 do not know whether the legal guardians have been made familiar with their child's educational support plan is a disgrace from an educational point of view. Cooperation is an integral part of the plan; the parents, in their home environments, are expected to build on the teacher's work, to develop it so as to mutually cooperate in the interest of the child's development. The issue of providing this support to children remains unresolved.

Also, the level of awareness of the need to develop educational support plans was examined. All respondents in both groups agreed that it should be the school developing the plan-where required by the special educational needs of any child. There were differences as to who they thought the initiator of the plan was and upon whose recommendation the plans are developed:

a) school counselling establishments - 25 RTs (30.49\%), 62 RSs (75.61\%),

b) the child's legal guardian by submitting a request - 75 RTs $(91.46 \%)$, 62 RSs $(75.61 \%)$,

c) other authorities - 28 RTs (34.15\%), 55 RSs (67.07\%), (28),

while the correct answer is $a)+b)$, which was only ticked by 12 RT respondents (14.63\%) and 17 RS respondents (20.73\%). The differences in the numbers of respondents in the two groups who ticked the correct answer are not statistically significant; what is significant, though, is the fact that such a low number of respondents in both groups were correctly informed as to who is in charge of initiating the production of PPPs by law.

According to 75 RTs (91.46\%) and 38 RSs (46.34\%), the PPPs formulate the objective of the support and the method of evaluating the progress achieved by the child. As expected, statistically (and realistically) the differences in the frequencies reported for each of the group with regard to the formulation of objectives and methods of evaluating the child's progress are significant.

Considering the required quality of joint education, the survey also sought to establish the respondents' awareness of the content of PPPs. The PPPs mainly provide information on (a) adjustments to the content of children's education, (b) time allocation and content distribution of tuition; (c) modifications to the methods and forms of tuition and child evaluation; 
(d) any modifications of the outcomes of the children's education process. A multiple option item was presented to the respondents.

$19(23.17 \%)$ RTs and $25(30.49 \%)$ RSs ticked all of the options, 23 RTs $(28.05 \%)$ and 11 RSs $(13,41 \%)$ ticked two options, 17 RTs $(20.73 \%)$ and 45 $(54.88 \%)$ RSs ticked three options, 23 respondents (T), i.e. $28.05 \%$, and 33 respondents (S), which accounts for $40.24 \%$, ticked only one of the options.

The differences in frequencies are statistically insignificant if the respondents who ticked all options and those who ticked one option only are concerned. On the contrary, the differences in frequencies become significant for the respondents who ticked two and three options. Realistically, however, any scenario than that where items (a) and (b) are ticked suggest a lack of awareness of the method in which PPPs are developed. 63 RTs (76.83\%) and 57 RSs (69.51\%) have incomplete knowledge of how PPPs are developed. The percentage of incompletely informed experts in this field of joint children's education is very high.

The teacher assistant instrument will amount to a very important supporting measure, both for the children and, ultimately, for the teachers in the educational landscape. As part of the next step in the questionnaire survey, the respondents were required to pick a correct statement from the options provided. 17 RTs $(20.73 \%)$ and 11 RSs $(13.41 \%)$ believe teacher assistants will provide support to other educational workers when educating children with SENs, assisting to them when organising and conducting tuition.

15 RTs $(18.29 \%)$ and 17 RSs $(20.73 \%)$ believe that teacher assistants work either with the child concerned or with other children separately - as required,

35 RTs $(42.68 \%)$ and 48 RSs (58.54\%) said that the teacher assistant works - as required - either with the child or the other children within the class or group as instructed by another educational worker,

15 RTs $(18.29 \%)$ and 6 RSs $(7.32 \%)$ RS are convinced that the teacher assistant cooperates with the child or with the other children in the class as necessary.

Statistically speaking, the differences in frequencies between the respondent groups are not significant for any of the opinions expressed. The distribution of the opinions, however, does not attest to the respondents being well informed, although the truth is that the highest frequency was reported for the claim that the "teacher assistant works - as required - with the child concerned or the other children within the class or group as instructed by another educational worker".

This item is closely related in terms of meaning to the following multiple option item which targeted the main activities of teacher assistants. 
The claim that the main activities of teacher assistants also include other activities defined under yet another legal regulation was not ticked by any of the respondents in the RT group. It may be assumed that the respondents thought this was too illogical to be true. Yet, unfortunately, it was the correct answer. The activities of teacher assistants are addressed under multiple regulations. But also in the RS group, there were only 2 respondents who ticked this option.

Most respondents, [63 RTs (76.83\%) and 75 RSs (91.46\%), ] believe teacher assistants' main activities include assisting the child in adapting to the school environment.

The claim under the previous item that teacher assistants are required to provide support to another educational worker in the course of educating children with SENs,[17 RTs (20.73\%) and 11 RSs (13.41\%) ], does not correspond to what the respondents said now. 45 RTs (54.88\%) and 38 RSs $(46.34 \%)$ indicated as one of the main activities of teacher assistants assisting the teachers in the course of their educational activity and assistance in the teacher's communication with the children, the children's legal guardians and with the community from which the children come.

Assisting the child during the educational process and providing the necessary help for the children to take care of themselves and move around during the educational process and educational events were ticked by the same number of respondents in both groups, [81 RTs and $82 \mathrm{RSs}$ ]. With the exception of one vote, this amounts to all votes in both respondent groups. This multiple-option item, which focused on the main activities of teacher assistants showed the respondents' informational insecurity in this respect.

\section{Conclusion}

Initial data were obtained on how well-informed kindergarten teachers, principals and head teachers are regarding the changes in educating children with special educational needs, namely with regard to joint education of all children within the main educational stream at kindergartens. The questions we considered important were answered by groups of respondents who work with children on an everyday basis and who directly face the consequences of the changes in their professional lives.

A specific answer was always sought for the main survey question in successive steps. The answers obtained are presented along with their frequencies and percentages. Once they were processed statistically, conclusions were drawn for all items. 
The range of information kindergarten teachers, principals and head teachers should absorb for the successful discharge of their professional duties, is broad and ever-changing. The items of information targeted by our survey were new. No significant differences in the level of awareness of the current changes in the educational system related to joint education of children at kindergartens have been identified between the group of respondents who are currently enrolled in the aforementioned study programme and the group composed of respondents who are currently not enrolled as students. The subject of the survey however pointed out knowledge gaps for both groups of respondents. All stakeholders, whose competences include providing information on joint children's education to this population of educational workers should intensify their efforts with regard to the content examined by this survey. This also applies to the responsible staff members involved in the Kindergarten Teacher Training study programme at the Pedagogical Faculty of the University of Ostrava.

\section{BIBLIOGRAPHY}

Brugger W., Filosofický slovnik, Naše vojsko, Praha1994.

Michalík J., Baslerová P., Felcmanová L., Podpưrná opatření ve vzdělávání, Člověk v tísni, o. p. s., Praha 2015.

Ministry of Education, Youth and Sport. Act No. 561/2004 Coll. on preschool, primary, secondary, higher vocational and other education (Education Act), http://www.msmt.cz/ dokumenty-3/skolsky-zakon-ve-zneni-ucinnem-od-1-1-2017-do-31-8-2017, [available: 18 January 2017].

Ministry of Education, Youth and Sport. Decree No. 27/2016 Coll., on the education of pupils with special educational needs and gifted pupils, http://www.msmt.cz/dokumenty3/vyhlaska-c-27-2016-sb-o-vzdelavani-zaku-se-specialnimi, [available: 18 January 2017].

Ministry of Education, Youth and Sport. Decree No. 72/2005 Coll. concerning the provision of c counselling services at schools and school counselling establishments, https://www. zakonyprolidi.cz/cs/2005-72,[available: 18.01.2017].

Open Society Fund Praha. Do all children have equal educational opportunities? http:/ / osf.cz/cs/co-delame/vzdelavani-deti-a-mladych-

lidi/?utm_source=adwords\&utm_medium =ppc\&utm_content=otevrenaskola\&utm_ campaign=S_Podporte\&gclid=CjwKEAiA7ejCBRDlp8uF6ezPnjoSJAAPED7MD57vm56wy8v4W1YAL8zTSo0AbC-WrprylpFvmCo8BoCSq_w_wcB), [available: 18 January 2017].

Průcha J., Walterová E., Mareš J., Pedagogický slovník, Portál, Praha 2008. 